\title{
PENILAIAN KELAYAKAN EKOWISATA KARST CIBADAK DI KECAMATAN CIAMPEA KABUPATEN BOGOR
}

\author{
(Study of Feasibility in Cibadak Karst Ecotourism in Ciampea District, Bogor Regency)
}

\author{
RATNA SARI HASIBUAN ${ }^{*}$ DAN KEN DARA CITA \\ Program Studi Kehutanan Universitas Nusa Bangsa Bogor, Tanah Sereal, Kota Bogor, Indonesia 16166
}

*Email: ratna@unb.ac.id

Diterima 24 Juli 2019 / Disetujui 13 Mei 2020

\begin{abstract}
Cibadak Karst needs feasibility assessment as a tourist destination. The objective was to determine the feasibility of tourism, especially for the exokarst in Cibadak Village. The research used Nature Tourism Attraction (DTWA) scoring for the analysis. The results indicated that the Cibadak karst Ecotourism is worthy to be developed as a tourist destination with the total score of 77,87\%. The area covers some atraction namely tracking tours, educational tours and camping ground. Other tourism attractions that could enhance the area feasibility as a tourism site, include: observation of karst flora and fauna, outbound, cave search, observation of cave fauna of the cave.
\end{abstract}

Keywords: Cibadak karst, feasibility, natural tourist attraction

\section{ABSTRAK}

Kawasan Karst Cibadak perlu dilakukan penilaian kelayakan ekowisata untuk mengetahui apakah kawasan ini layak dikembangkan atau tidak. Tujuan penelitian adalah menilai kelayakan ekowisata Karst Cibadak terutama area eksokarst yang ada di Desa Cibadak. Metode penelitian adalah deskriptif dengan menggunakan analisa penskoringan Daya Tarik Wisata Alam (DTWA). Hasil penelitian meunjukkan bahwa kawasan Karst Cibadak layak dikembangkan sebagai daerah tujuan ekowisata dengan nilai 77,87\%. Daya tarik wisata alam di kawasan Karst Cibadak antara lain: wisata tracking, wisata edukasi dan camping ground. Daya Tarik wisata budaya di kawasan Karst Cibadak yaitu adanya bekas peninggalan Kerajaan Siliwangi. Kawasan ini perlu ditambahkan atraksi wisata lain seperti pengamatan flora dan fauna karst, outbond, penelusuran gua, pengamatan fauna gua agar meningkatkan nilai kelayakan Karst Cibadak.

Kata kunci: daya tarik wisata alam, karst Cibadak, kelayakan

\section{PENDAHULUAN}

Lanskap gunung kapur merupakan salah satu bentukan wilayah yang memiliki keragaman tinggi dalam ekosistem, yang meliputi bentuk lahan, stratifikasi batuan, vegetasi dan lingkungan (Novian 2010). Keragaman tersebut merupakan daya tarik utama yang menjadikan gunung kapur sebagai wilayah yang berpotensi untuk dikembangkan dalam sektor pariwisata. Menurut Peraturan Menteri Energi dan Sumber Daya Mineral Nomor 17 Tahun 2012; Rusyani (2014); Endarto et al. (2016) terbentuknya karst karena adanya proses pelarutan oleh air hujan pada batuan karbonat (batu gamping).

Gunung kapur di Kecamatan Ciampea terletak di beberapa desa seperti Desa Cibadak, Ciampea dan Bojong Rangkas. Keberadaan karst Cibadak perlu dipertahankan melalui upaya pengelolaan dan pemanfaatan. Hal tersebut sejalan dengan rencana Pemerintah Daerah Kabupaten Bogor untuk melakukan optimalisasi Karst Cibadak. Menurut Novian (2010), di kawasan karst Cibadak berlangsung kegiatan ekslpoitasi batu kapur yang tidak terkendali, agar tidak menimbulkan masalah antar kepentingan ekologis dan kepentingan sosial ekonomi masyarakat, maka perlu dilakukan penilaian kelayakan untuk menentukan apakah kawasan ini layak dikembangkan sebagai tempat wisata.

Eksploitasi batu kapur yang dilakukan oleh masyarakat dikhawatirkan akan merusak gua-gua yang ada, mengeringkan sumber mata air, dan menurunkan keanekaragaman hayati sehingga dapat menurunkan kualitas lingkungan. Sebagai contoh, hasil penelitian Endarto et al. (2016) menyebutkan bahwa kerusakan karst akibat penambangan pada DAS Bribin Hulu Kabupaten Gunung Kidul Daerah Istimewa Yogyakarta yaitu terjadinya kerusakan pada gua, tutupan vegetasi, kondisi mata air dan bangunan di atas permukaan karst. Kerusakan tertinggi pada Desa Bedoyo, Desa Kenteng dan Karangasem dengan luas 922,27 Ha. Selain itu, terdapat juga pada Desa Sawahan, Desa Ponjong, dan Desa Sumbergiri dengan luas 9.424,24 Ha. Sementara itu, menurut Khairani (2017), terdapat peningkatan kesejahteraan rumah tangga pada pemanfaatan karst antara Desa Bejiharjo dan Desa Bedoyo Kabupaten Gunung Kidul. Desa Bejiharjo memanfaatkan karst sebagai areal wisata alam sedangkan Desa Bedoyo memanfaatkan karst sebagai bahan tambang. 
Tujuan penelitian adalah menilai kelayakan pengembangan ekowisata Karst Cibadak khususnya pada eksokarst Puncak Lalalna di Desa Cibadak. Hasil penelitian diharapankan dapat menjadi perhatian berbagai stakeholder agar masyarakat tidak mengambil batu kapur dan masyarakat sebagai penambang batu kapur dapat beralih menjadi pengelola wisata.

\section{METODE PENELITIAN}

Penelitian dilaksanakan di kawasan Karst Cibadak Kecamatan Ciampea Kabupaten Bogor pada April-Juli 2019. Gunung kapur Cibadak Ciampea secara geografis terletak pada $106^{\circ} 32^{\prime} 0$ " $\mathrm{BT}-106^{\circ} 35^{\prime} 46^{\prime \prime} \mathrm{BT}$ dan $6^{\circ}$ 36' 0" LS - 6 ${ }^{\circ} 55^{\prime} 46^{\prime \prime}$ LS.

Lokasi penelitian secara khusus adalah Puncak Lalana yang terdapat di Desa Cibadak (Gambar 1). Lokasi ini dipilih karena akses yang mudah dari Kota Bogor, jarak ke Puncak Lalana sekitar $500 \mathrm{~m}$ dari pos registrasi, dan banyak dikunjungi oleh wisatawan karena memiliki panorama yang indah dari atas Puncak Lalana. Alat yang digunakan adalah peta rupa bumi, peta Kecamatan Ciampea, alat tulis, kamera, laptop, kuesioner, GPS, dan Quantum GIS software.

Metode penelitian bersifat deskriptif dengan melakukan wawancara dan observasi lapang untuk mendapatkan data potensi wisata dan flora fauna yang ada. Potensi wisata dan flora fauna didapatkan dengan metode pengamatan cepat (rapid assesment) (Bismark 2011). Metode ini digunakan dengan mencatat jenis-jenis flora fauna yang ditemukan selama observasi dilakukan mulai dari pos registrasi sampai ke Puncak Lalana.

Wawancara adalah teknik pengumpulan data yang dilakukan melalui tatap muka dan tanya jawab langsung antara peneliti dan responden. Dalam penelitian ini, wawancara dilakukan kepada tiga kelompok responden yaitu:

a. Pengunjung, dilakukan dengan wawancara menggunakan kuesioner sebanyak 30 orang dengan kriteria pelajar;

b. Masyarakat sekitar dilakukan dengan wawancara menggunakan kuesioner sebanyak lima responden berdasarkan kategori masyarakat yang berhubungan langsung dengan lokasi wisata (Sekdes Kelurahan Cibadak, ketua RT, pemilik warung dan warga);

c. Pengelola, dilakukan dengan wawancara menggunakan kuesioner sebanyak tiga orang yang mengetahui mengenai kawasan Gunung Kapur (Dinas Pariwisata Kab. Bogor, Perum Perhutani, dan Pengelola Kawasan).

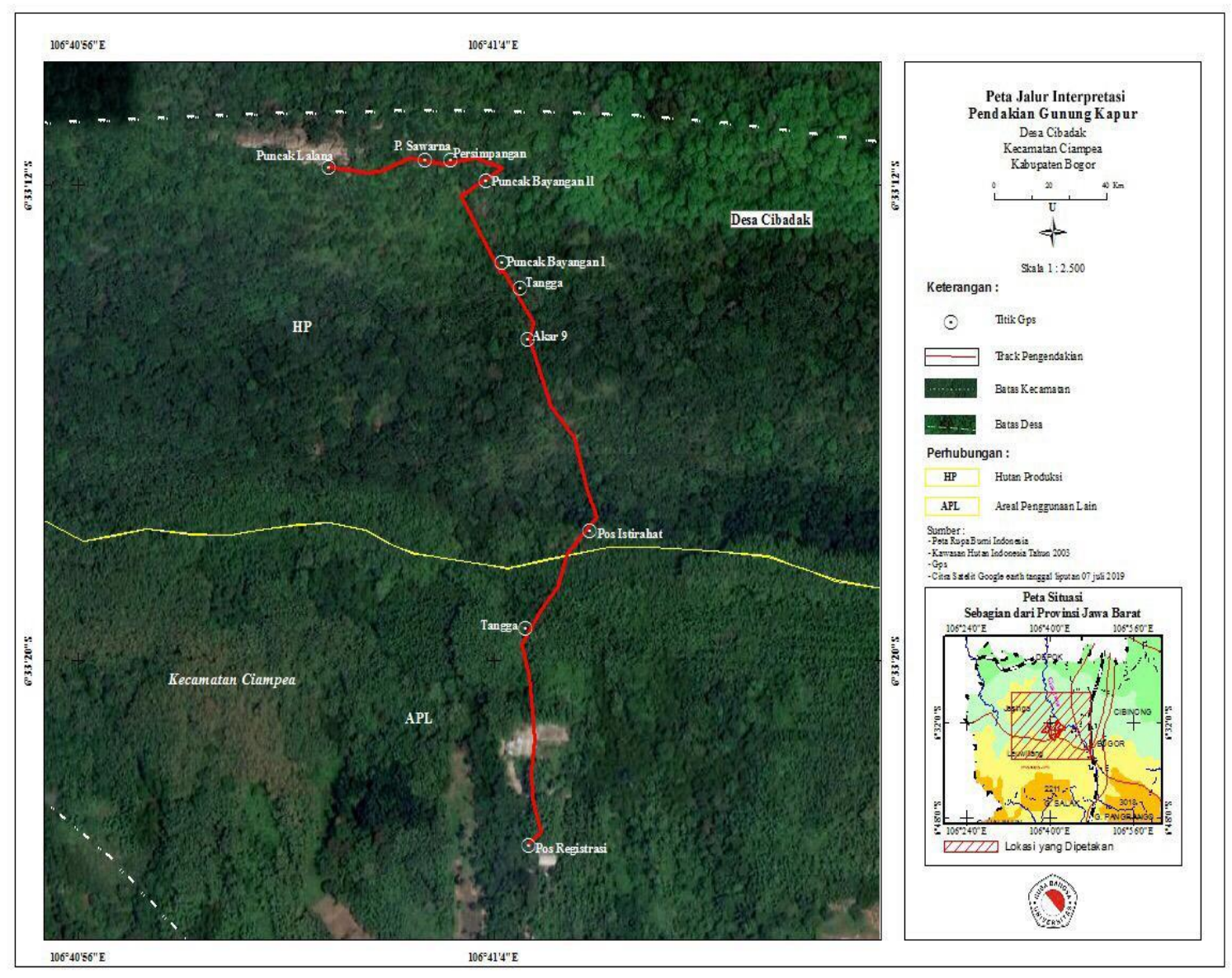

Gambar 1 Peta lokasi penelitian 
Komponen yang dicatat dan dinilai adalah:

a. Bobot 6 dari daya tarik meliputi keindahan alam dan keunikan, banyaknya sumbar daya alam yang menonjol, keutuhan sumberdaya alam, kenyamanan, kebersihan dan jenis kegiatan aktivitas wisata alam;

b. Bobot 5 dari aksesibilitas meliputi jarak dari kota ke lokasi wisata, kondisi jalan, tipe jalan dan waktu tempuh dari kota;

c. Bobot 3 dari sarana dan prasarana meliputi sarana prasarana penunjang yang ada dalam radius $5 \mathrm{~km}$ dari lokasi wisata.

Data kelerengan lokasi dilakukan dengan pengambilan titik-titik koordinat menggunakan GPS mulai dari pos registrasi sampai Puncak Lalana. Titik koordinat yang diperoleh kemudian dianalisis menggunakan software Quantum 2.1 dengan cara mengoverlay peta Kecamatan Ciampea dan Peta Rupa Bumi.

Obyek dan daya tarik yang telah diperoleh dianalisis sesuai dengan kriteria Daya Tarik Wisata Alam mengacu pada Dirjen PHKA (2003); Walimbo (2016); Sakdiah (2017); Zen et al. (2018). Jumlah nilai untuk satu kriteria dihitungan dengan menggunakan rumus

$$
\mathrm{S}=\mathrm{N} \times \mathrm{B}
$$

Keterangan:

$\mathrm{S}=$ skor/nilai suatu kriteria

$\mathrm{N}=$ jumlah nilai unsur-unsur pada kriteria

$\mathrm{B}=$ bobot nilai

Skor diperoleh dari hasil wawancara kepada tiga kelompok responden dengan rentang nilai antara 0-1 dan semua skor dijumlah. Skor yang diperoleh kemudian dibandingkan dengan skor total tertinggi suatu kriteria agar memperoleh tingkat kelayakan. Indeks kelayakan suatu kawasan ekowisata adalah sebagai berikut (Karsudi 2010):

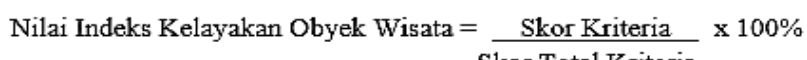
Skor Total Kriteria

Kriteria tingkat kelayakan adalah sebagai berikut:

1. Tingkat kelayakan $>66,6 \%$ : layak dikembangkan;

2. Tingkat kelayakan $33,3 \%-66,6 \%$ : belum layak dikembangkan;

3. Tingkat kelayakan $<33,3 \%$ : tidak layak dikembangkan.

\section{HASIL DAN PEMBAHASAN}

\section{Identifikasi Potensi Ekowisata}

\section{a. Daya tarik wisata}

Menurut Karsudi (2010), daya tarik adalah hal yang penting dalam pengembangan suatu kawasan ekowisata agar layak dikembangkan. Seorang wisatawan akan mengunjungi dan melihat secara langsung ke tempat yang memiliki daya tarik sehingga daya tarik merupakan faktor yang mempengaruhi seseorang untuk berkunjung ke suatu kawasan wisata. Ekowisata Karst Cibadak merupakan salah satu bentang pegunungan kapur yang ada di Kabupaten Bogor dengan jalur pendakian yang dianggap menantang dan cukup manarik terutama bagi pemanjat gunung atau pemanjat tebing pemula. Fauna yang dapat ditemukan sepanjang area ini adalah: monyet ekor panjang (Macaca fascicularis), wallet (Walet linchi) dan ular viper (Trimeresurus albolabris), sementara flora yang dijumpai meliputi jati (Tectona grandis), petai cina (Leucaena leucocephala), pisang (Musa sp.), rengas (Gluta renghas), klampis (Acacia tementosa), karet (Hevea brasiliensis), paku-pakuan (Nephrolepis sp.) dan ketela (Ipomoea sp.).

Tabel 1 merupakan hasil perhitungan penilaian daya tarik yang diperoleh dari hasil wawancara kepada tiga kelompok responden dengan rentang nilai antara 0-1. Tabel 1 mengindikasikan bahwa daya tarik ekowisata yang paling menonjol dengan total skor 180 adalah keindahan dan keunikan sumberdaya alam serta keutuhan sumberdaya alam, sedangkan nilai terendah adalah jenis kegiatan aktivitas wisata alam dengan total skor 90 .

Karst Cibadak memiliki keindahan dan keunikan sumber daya alam karena terletak tidak jauh dari pusat permukiman dan menghadirkan atmosfir yang unik dan artistik bagi wisatawan. Selain itu, kawasan ini juga memiliki nilai sosial budaya yang tinggi karena ditemukannya bekas peninggalan Kerajaan Siliwangi. Pada tahun 1981 di kawasan ini ditemukan lima buah arca. Saat ini kelima arca tersebut disimpan di Museum Pasir Angin. Kelima arca tersebut adalah patung 5, 4, 3, 2 dan 1. Pesan dari kelima arca tersebut adalah kawasan ini pernah ditempati atau dihuni kelompok masyarakat Pajajaran. Nama-nama arca tersebut di antaranya adalah Sangiyang Dewa Braja, Sangiyang Agung Dewa Suci, Sangiyang Mustika Dewa Domas dan Sangiyang Cupu Manik (Bogor daily 2017). Hasil penelitian Novian (2010), tahun 1971 peninggalan Purnawarman ditemukan pada Karst Cibadak yang terbuat dari emas putih.

Dari Puncak Lalana, pengunjung disajikan dengan panorama alam dan pemandangan artistik berupa hamparan gugusan gunung kapur yang khas (Gambar 2). Keindahan dan keunikan sumberdaya alam ini merupakan modal yang besar dalam upaya pengembangan wisata secara profesional kedepannya. Batuan pada Karst Cibadak berusia Miosen merupakan batuan yang tersusun dari batu gamping terumbu (reef), batu gamping koral terumbu, batu gamping lempungan dan batu gamping kristalin. Fenomena permukaan meliputi bentukan positif, seperti perbukitan karst bukit yang berbentuk kerucut. Puncak kerucut bisa membulat (Sinusoida) atau lancip (Karst conical), lekuk lekuk di antara perbukitan batu gamping membentuk dolina, baik terbuka maupun tertutup (Nuraini 2013). Menurut Novian (2010), batu gamping formasi Bojong Manik yang umurnya setara dengan miosen tengah terdapat di Kawasan Karst Cibadak. Menurut peta jenis batuan Jawa 
Barat tahun 2005, batuan yang terdapat pada Karst Cibadak terbagi menjadi beberapa jenis yaitu batuan gamping kuarter, dan batuan sedimen plio-plistosen.

Kenyaman memililiki total skor 150, yang merupakan skor kedua setelah jenis kegiatan wisata alam. Kenyamanan merupakan hal yang penting pada pengembangan wisata di kawasan karst. Hal ini karena kawasan karst memiliki tingkat bahaya yang tinggi karena kelerengan yang cukup curam. Berdasarkan peta bumi karst Cibadak terletak di ketinggian $\pm 385 \mathrm{~m}$ di atas permukaan laut dengan kelerengan 25-30\%. Berdasarkan klasifikasi lereng Kementerian Kehutanan (2013), kelas lereng di kawasan karst Cibadak yaitu kelerengan 3-8\% sebesar 3.209.483,8 $\mathrm{m}^{2}$, kelerengan 8$15 \%$ yaitu seluas $225.474,9 \mathrm{~m}^{2}$, kelerengan $15-30 \%$ dengan luas $371.144,8 \mathrm{~m}^{2}$, kelerengan $30-45 \%$ seluas 954.296.7 $\mathrm{m}^{2}$ dan kelerengan 45-65 seluas 3.800,8 $\mathrm{m}^{2}$ (Gambar 3).

Tabel 1 Hasil penilaian komponen daya tarik wisata

\begin{tabular}{llccc}
\hline \multirow{2}{*}{ No } & \multicolumn{1}{c}{ Unsur/Sub unsur } & \multicolumn{2}{c}{ Nilai } \\
& & Bobot & Nilai & Skor total \\
\hline 1 & Keindahan alam dan keunikan sumberdaya alam & 6 & 30 & 180 \\
2 & Banyaknya sumberdaya yang menonjol & 6 & 30 & 180 \\
3 & Keutuhan sumberdaya alam & 6 & 30 & 180 \\
4 & Kenyamanan & 6 & 25 & 150 \\
5 & Kebersihan lokasi & 6 & 25 & 150 \\
6 & Jenis kegiatan wisata alam & 6 & 15 & 90 \\
\hline & Jumlah & & 155 & 930 \\
\hline
\end{tabular}

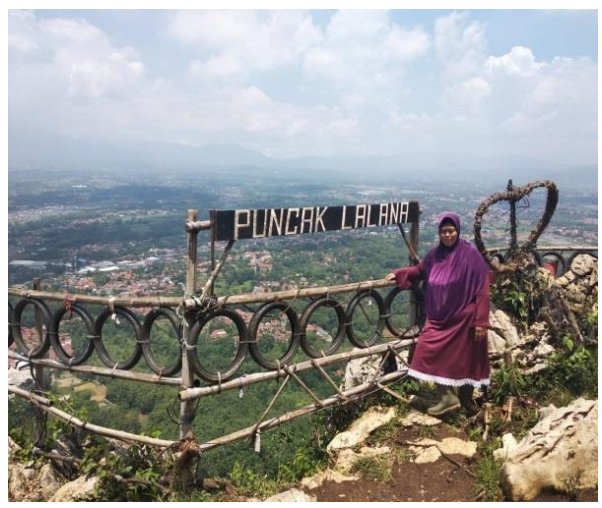

Gambar 2 Puncak Lalana
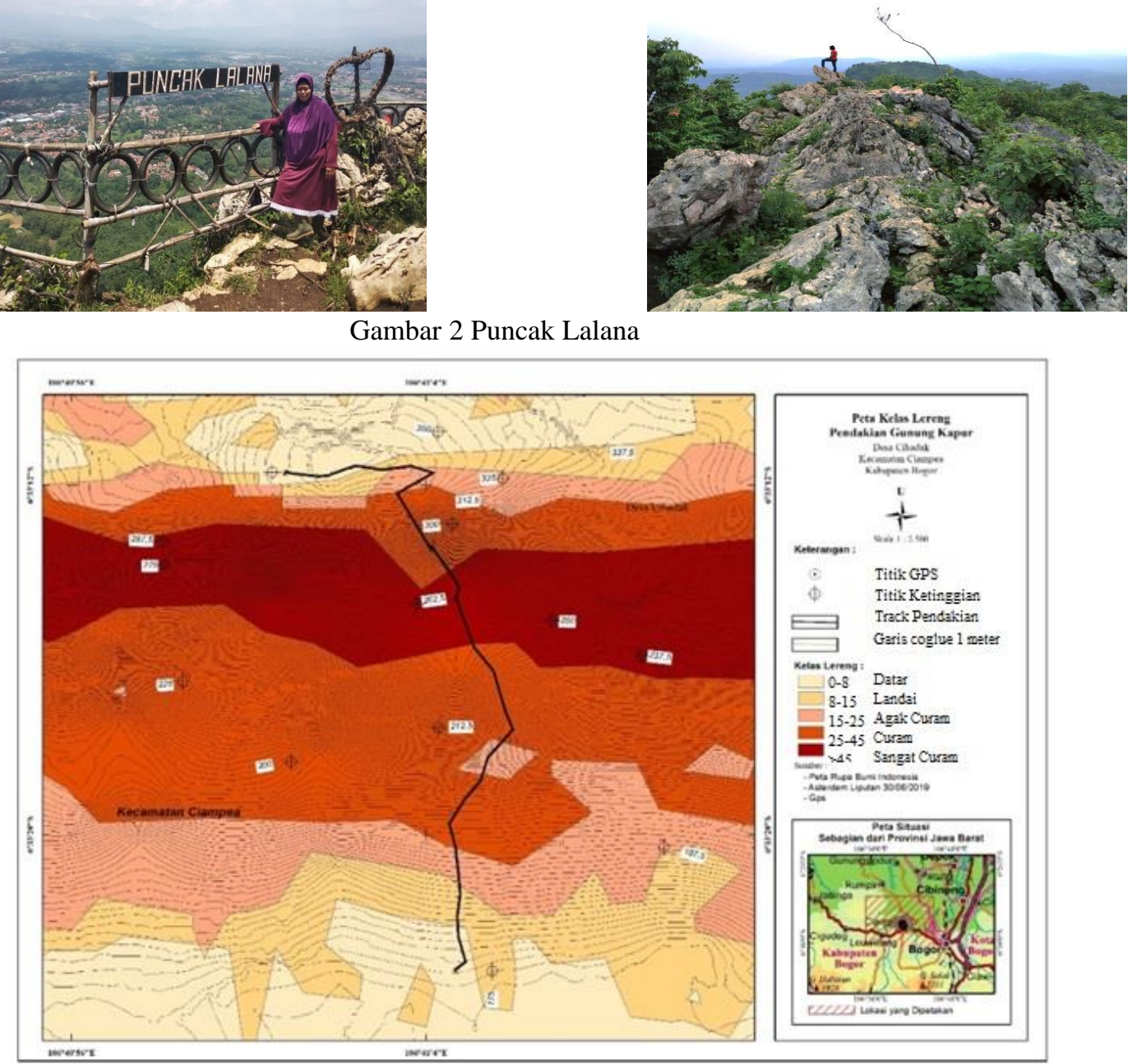

Gambar 3 Peta kelas lereng gunung kapur 
Masyarakat sebagai pengelola telah menyediakan tali pengaman untuk berpegangan pada jalur pendakian (Gambar 4) untuk membuat pengunjung merasa nyaman dalam berwisata. Peralatan keamanan yang disediakan pengelola masih sangat sederhana, sehingga sangat diperlukan peralatan safety yang sesuai dan memadai seperti hardness, tali karmantel, webbing dan sebagainya. Lokasi yang sangat membutuhkan peralatan safety adalah Akar Sembilan dengan koodinat 6 $6^{\circ} 33^{\prime} 14.59^{\prime}$ 'S $106^{\circ} 41^{\prime} 4.65^{\prime}$ 'T, Melehoy pada koordinat 6 63'13.32' 'S 106 41'4.16', T, Tanjakan Cinta pada koordinat 6 33'11.96' S - 106 41'3.83''T dan Tebing Sawarna pada koordinat 6०33'11.60's - 10641'2.69''T. Pengelola juga menyediakan walkie talkie sebagai alat komunikasi untuk mengatur pengunjung dan keadaan darurat apabila terjadi kecelakaan pada saat pendakian (Gambar 5).

Menurut Suharto (2016) resiko wisatawan apabila berada pada di lokasi wisata yaitu:

1. Resiko karena pencurian, kejahatan, pengrusakan, penodongan, dan penculikan;

2. Resiko dari binatang buas, tanaman beracun, dan tertimpa pohon;

3. Resiko akibat kecelakaan darat ataupun air, terjatuh, dan kebakaran.

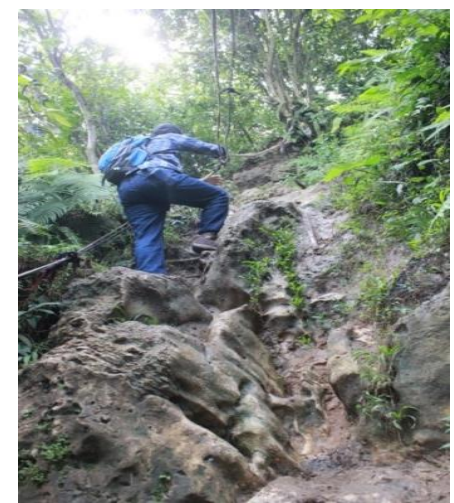

Gambar 4 Pengaman tali pada jalur pendakian

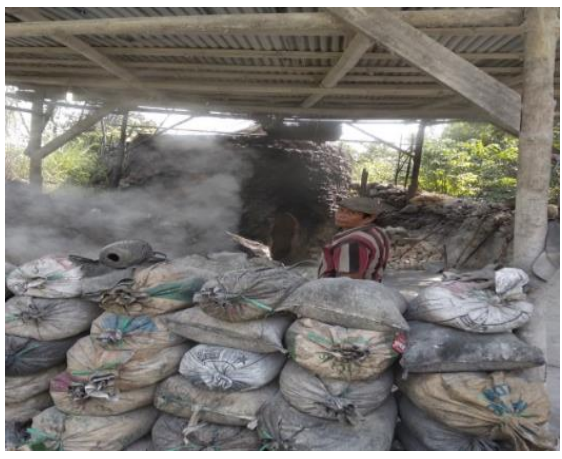

Pengelola dan stakeholder lainnya bertanggung jawab terhadap keamanan dan keselamatan pengunjung karena sektor pariwisata memberikan kontribusi pada kemajuan suatu daerah. Rasa nyaman yang diberikan oleh pengelola akan berdampak positif bagi destinasi wisata yang dikelolanya. Citra positif yang diberikan oleh suatu destinasi wisata berhubungan dengan banyak faktor seperti faktor pelayanan, lokasi, fasilitas, tanggungjawab pengelola atas keselamatan dan keamanan pengunjung, faktor berbagai resiko terhadap atraksi yang diberikan oleh pengelola (Suharto 2016). Peran masyarakat dalam hal memberikan rasa nyaman pada pengunjung sangatlah besar. Apabila pengunjung akan melakukan tracking, pengelola akan memberikan pengarahan terlebih dahulu mengenai jalur yang ada dan apabila terjadi kecelakaan apa yang akan dilakukan oleh pengunjung untuk dengan segera.

Aspek kebersihan lokasi menjadi pertimbangan dalam menentukan lokasi wisata dengan total skor 150 . Pengembangan ekowisata di Gunung Kapur saat ini masih memiliki kendala dalam pengelolaan kebersihan karena pada jalur menuju kawasan ekowisata terdapat tempat pembakaran kapur yang dinilai kurang menarik dan dari segi kebersihan sehingga dapat mengganggu kenyamanan wisatawan (Gambar 6).

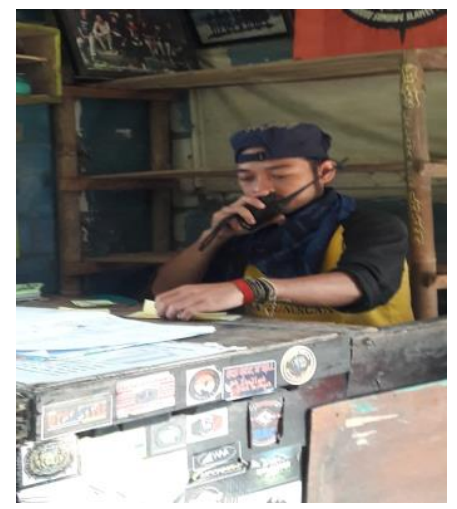

Gambar 5 Salah satu pengelola wisata yang berkoordinasi dengan petugas lapang

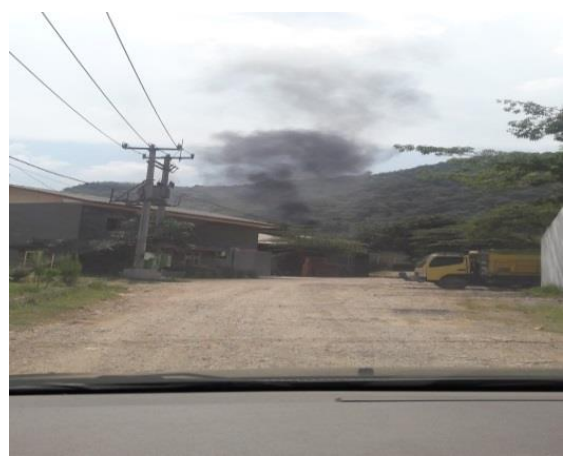

Gambar 6 Pembakaran kapur di sekitar lokasi wisata 
Nilai total skoring komponen daya tarik wisata yang terkecil adalah jenis kegiatan wisata alam dengan nilai 90. Keterbatasan kegiatan wisata alam yang dapat dilakukan merupakan faktor penyebab rendahnya skor untuk unsur ini. Jenis kegiatan wisata alam merupakan kegiatan-kegiatan yang bisa dilakukan oleh pengunjung saat berada di kawasan wisata, sehingga pengunjung tidak merasa bosan. Beberapa kegiatan wisata alam yang dapat dilakukan antara lain : menikmati keindahan gugusan gunung kapur, selfie/swafoto dari Puncak Lalana, tracking, berkemah, dan pengamatan atraksi satwa dalam hal ini adalah monyet ekor panjang.

\section{b. Aksesibilitas}

Semua jenis sarana transportasi yang mendukung pergerakan wisatawan dari tempat asal ke lokasi wisata termasuk hal yang penting. Sarana transportasi termasuk kondisi jalan dan jarak dari kota ke lokasi wisata merupakan aksesibilitas yang perlu diperhatikan (Tabel 2). Salah satu aspek berkembangnya tempat wisata adalah aksesibilitas karena tidak mungkin wisatawan megunjungi objek wisata apabila aksesnya sulit dijangkau (Abdulhaji 2016). Hal yang sama disebutkan oleh Nawangsari et al. (2018) yang menyatakan bahwa dengan adanya aksesibilitas yang baik maka pengunjung akan mudah mencapai lokasi wisata.

Berdasarkan Tabel 2, penilaian komponen aksesibilitas berupa kondisi tipe jalan dan waktu tempuh dari pusat kota memiliki total skoring masing-masing sebesar 150, sedangkan jarak dari kota mendapat nilai 100 yang merupakan nilai terendah, karena kawasan ini dapat ditempuh dari Kota Bogor sekitar 1-2 jam. Ekowisata karst gunung kapur mudah dicapai karena letaknya strategis sekitar 1,2 km dari Jalan Raya Cibungbulang. Akses utama menuju ekowisata Karst Cibadak terletak di Desa Cibadak Gg. Ashibiyan yaitu berup jalan berbatu semi permanen dengan lebar $3-5 \mathrm{~m}$, namun mengingat jalannya yang masih berbatu, maka bus ukuran besar tidak direkomendasikan untuk naik ke lokasi pos jaga pengelola ekowisata Karst Cibadak (Gambar 7). Lokasi pos pengelola dapat dicapai pengunjung menggunakan kendaraan roda dua dan roda empat maupun dengan berjalan kaki, sedangkan untuk jalur sirkulasi ekowisata Karst Cibadak hanya memiliki satu jalur yang digunakan untuk jalur sirkulasi kendaraan dan pejalan kaki.

\section{c. Akomodasi}

Sakdiah (2017) menyatakan bahwa akomodasi merupakan kebutuhan wisatawan yang penting dalam berwisata ke suatu tempat, terutama kawasan tersebut jauh dari pusat kota. Penilaian terhadap akomodasi saat ini belum penting karena mayoritas pengunjung (65\%) berasal dari Bogor, sedangkan 35\% berasal dari Jakarta, Tangerang dan Bandung.

Jarak dari kota Bogor ke lokasi Ekowisata Karst Cibadak dapat ditempuh sekitar 2 jam dari kota Bogor, dengan aksesibilitas yang mudah dan alternatif atraksi yang tidak bervariasi, menyebabkan sebagian besar pengunjung $(60 \%)$ hanya menghabiskan waktu kunjungan 1-3 jam, sehingga kebutuhan atas akomodasi penginapan tidak terlalu dibutuhkan oleh pengunjung yang datang ke kawasan ekowisata Karst Cibadak. Pengunjung membutuhkan atraksi wisata yang lebih bervariasi sehingga tidak merasa bosan. Hasil penelitian Widodo (2017) menunjukkan bahwa aktivitas wisata yang kurang bervariasi dapat menyebabkan wisatawan jenuh, dan mengakibatkan kegiatan wisata tidak berjalan dengan baik. Menurut Prawerti et al. (2015) jumlah pengunjung Candidasa, Kabupaten Karangasem, Bali turun drastis dari 7.473 pengunjung pada tahun 2010 menjadi 332 wisatawan tahun 2012, akibat terbatasnya aktivitas berwisata, sehingga waktu kunjungan di lokasi wisata juga tidak lama.

\section{d. Sarana Prasarana}

Salah satu komponen penting dalam suatu perjalanan wisata adalah amenitas atau kenyamanan yang dirasakan di suatu kawasan wisata. Ekowisata Karst Cibadak dilengkapi dengan fasilitas walaupun masih sangat terbatas dan perlu dilakukan pembangunan sarana dan prasarana. Saat ini hanya beberapa sarana tersedia seperti warung, toilet, tempat parkir, ruang pertemuan semi permanen, namun masih dalam kondisi yang masih perlu perbaikan (Gambar 8 dan 9). Penilaian wisatawan terhadap keterediaan sarana prasarana di Ekowisata Karst Cibadak disajikan pada Tabel 4.

Tabel 2. Hasil penilaian komponen aksesibilitas

\begin{tabular}{clccc}
\hline \multicolumn{1}{c}{ No Unsur/Sub unsur } & \multicolumn{2}{c}{ Nilai } \\
\cline { 3 - 5 } & \multicolumn{1}{c}{ Nondisi jalan } & Bobot & Nilai & Skor total \\
\hline 1 & Jarak dari kota & 5 & 30 & 150 \\
2 & Tipe jalan & 5 & 20 & 100 \\
3 & Waktu tempuh dari pusat kota & 5 & 30 & 150 \\
4 & Jumlah & & 25 & 125 \\
\hline
\end{tabular}



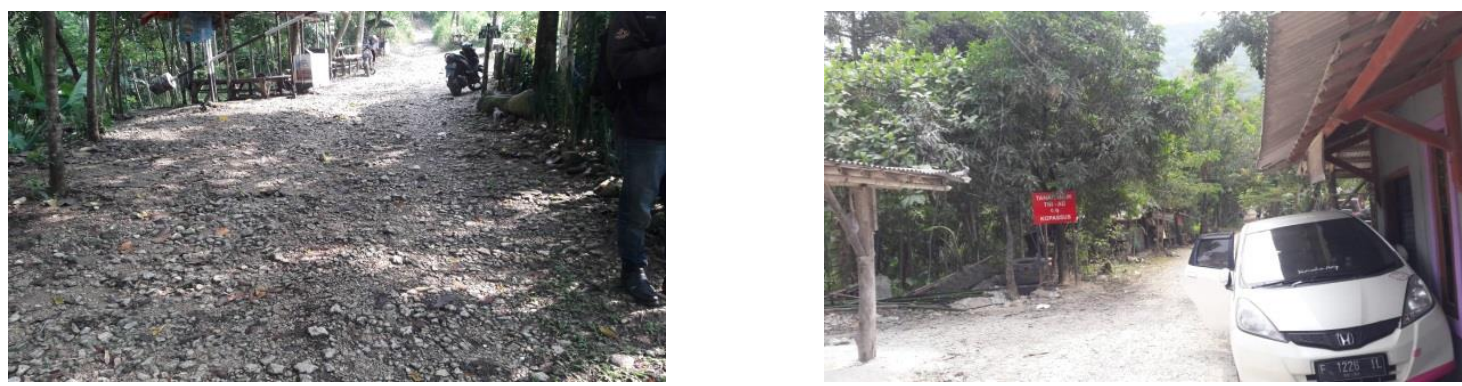

Gambar 7 Akses menuju lokasi wisata

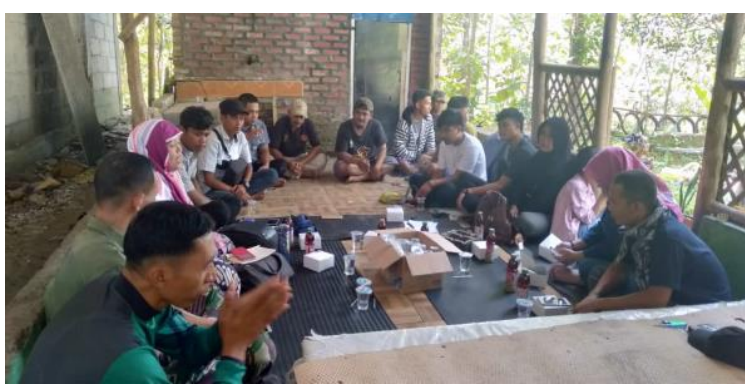

Gambar 8 Gedung pertemuan

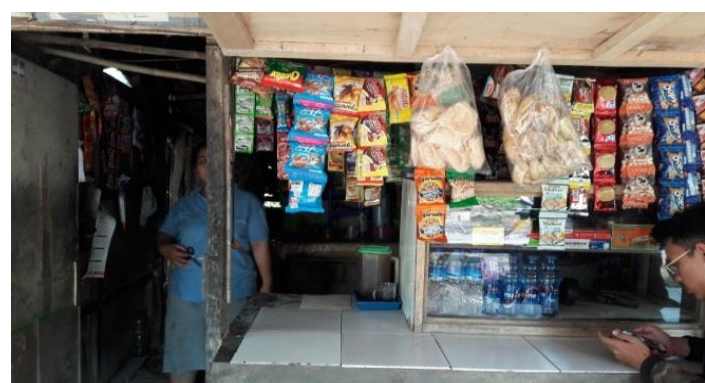

Gambar 9 Warung warga di lokasi penelitian

Tabel 4 Hasil penilaian komponen sarana dan prasarana

\begin{tabular}{cccccc}
\hline & & Unsur/Sub unsur & \multicolumn{3}{c}{ Nilai } \\
\cline { 3 - 5 } No & & Bobot & Nilai & Skor total \\
\hline 1 & Sarana & 3 & 30 & 90 \\
2 & Prasarana & 3 & 30 & 90 \\
\hline \multicolumn{2}{l}{} & Jumlah & & 60 & 180 \\
\hline
\end{tabular}

Berdasarkan Tabel 4, sub unsur sarana memiliki nilai skor 90. Saat ini komponen sarana dan prasarana di Ekowisata Karst Cibadak dapat dikategorikan masih terbatas. Menurut Abdulhaji (2016), tempat wisata dapat berkualitas apabila fasilitas objek wisatanya baik. Citra objek wisata akan semakin baik apabila semakin baik fasilitas yang diberikan pengelola. Pembangunan sarana prasarana sangat diperlukan untuk meningkatkan skor terutama pada pos registrasi, mengingat pos registrasi yang masih semi permanen. Jalur pendakian juga perlu perhatian yang khusus, mengingat curamnya jalur yang harus dilalui oleh pengunjung. Perlunya pengontrolan dan penambahan tali pengaman yang ada sepanjang jalur pendakian sehingga membuat nyaman bagi pengunjung (Suharto 2016), selain itu pada Puncak Lalana juga perlu dibangun toilet, mengingat belum adanya toilet yang dibutuhkan bagi para pengunjung, terutama pengunjung yang akan camping. Aktivitas wisata lain juga perlu ditambahkan seperti pengamatan flora dan fauna karst, outbond, penelusuran gua, pengamatan fauna gua, mengingat adanya beberapa gua yang ada pada Ekowisata Karst Cibadak seperti Gua AC (Gua Cibiuk) (Novian 2010).

\section{Penilaian Kelayakan dan Pengelolaan Ekowisata Karst Cibadak}

Penilaian kelayakan DTWA di Ekowisata Karst Cibadak meliputi tiga kriteria yaitu daya tarik, aksesibilitas, dan sarana dan prasarana. Penilaian kelayakan terhadap komponen-komponen wisata alam di Ekowisata Karst Cibadak dapat dilihat pada Tabel 5. Tabel 5 menunjukkan bahwa Ekowisata Karst Cibadak layak dikembangkan sebagai tujuan wisata dengan indeks sebesar 77,87\%.

Untuk kriteria daya tarik, kawasan ini sudah memiliki daya tarik yang bernilai tinggi sebesar $86,11 \%$. Hal ini menunjukan bahwa daya tarik Ekowisata Karst Cibadak tersebut sangat berpotensi dan layak untuk dikembangkan menjadi lebih baik lagi pengelolaannya. Demikian halnya dengan aksesibilitas yang juga memiliki nilai tinggi yaitu $87,50 \%$, sedangkan sarana dan prasarana memiliki nilai yang rendah yaitu $60 \%$ karena belum dikembangkannya sarana dan prasarana penunjang. Di kawasan Ekowisata Karst Cibadak hanya terdapat beberapa fasilitas sarana dan prasarana penunjang berupa toilet, tempat parkir, camping ground dan ruang pertemuan yang masih dalam kondisi semi permenen dan perlu adanya pembangunan fisik pada lokasi kawasan wisata. 
Tabel 5 Hasil penilaian DTWA Ekowisata Karst Cibadak

\begin{tabular}{clcccccc}
\hline No & Kriteria & Bobot & Nilai $*$ & Skor** & Skor Max $* * *$ & Indeks $(\%) * * * *$ & Keterangan \\
\hline 1 & Daya tarik & 6 & 155 & 930 & 1080 & 86,11 & Layak dikembangkan \\
\hline 2 & Aksesibilitas & 5 & 105 & 525 & 600 & 87,50 & Layak dikembangkan \\
\hline 3 & Sarana dan prasarana & 3 & 60 & 180 & 300 & 60,00 & Belum layak dikembangkan \\
\hline & Tingkat kelayakan & & & & 77,87 & Layak dikembangkan \\
\hline
\end{tabular}

Ket : (*Hasil penilaian terhadap objek dan daya tarik wisata; ( **Perkalian antara bobot dengan nilai; (***Skor tertinggi untuk setiap kriteria; (****Indeks kelayakan: perbandingan skor dengan skor tertinggi dalam \%)

Dari hasil analisis yang sudah dilakukan terhadap kawasan Ekowisata Karst Cibadak dapat diketahui bahwa lokasi tersebut berpeluang untuk dijadikan sebagai salah satu daerah tujuan wisata karena memberi penawaran yang baik dari kriteria daya tarik wisata dan aksesibilitas. Saat ini Ekowisata Karst Desa Cibadak Kecamatan Ciampea Kabupaten Bogor dikelola oleh warga masyarakat RW 06 dengan jumlah pengelola sebanyak kurang lebih 15 (lima belas) orang sejak bulan Oktober 2015. Awalnya masyarakat sekitar Ekowisata Karst Cibadak hanya menggunakan kawasan tersebut sebagai tempat untuk berekreasi namun setelah melihat bahwa Ekowisata Karst Cibadak memiliki potensi dikembangkan sebagai tujuan wisata, maka warga RW 06 yang tergabung dalam kelompok MACAKAL mulai membuka jalur untuk pendakian.

Pengelolaan wisata yang berada di kawasan Karst Cibadak dikoordinasi oleh seorang kepala pengelola. Pengelolaan wisata yang baik akan berdampak positif karena dengan adanya sistem kelola yang sesuai dengan standar kepariwisataan akan memberikan keuntungan baik bagi pengelola, pengunjung maupun masyarakat sekitar. Pengelolaan Karst Cibadak dilakukan dengan cara bergantian, karena pengelola yang merupakan masyarakat Desa Cibadak mempunyai pekerjaan tetap selain sebagai pengelola wisata. Pendapatan yang dihasilkan dari penerimaan tiket masuk kawasan karst belum mencukupi apabila pengelola bekerja secara penuh waktu (tetap) dikawasan Karst Cibadak. Dari hasil kuesioner pada pengelola kawasan wisata Karst Cibadak, sebagian besar pengelola bekerja sebagai buruh di pertambangan dan pabrik $(66,66 \%)$. Tingkat pendidikan pengelola sebagian besar $(66,66 \%)$ lulusan SMA dan $33,33 \%$ lulusan D3. Pengelola semuanya berjenis kelamin laki-laki dan sudah berkeluarga.

Partisipasi masyarakat sangat penting dalam hal pengelolaan ekowisata terutama masyarakat yang berhubungan langsung dengan kawasan. Partisipasi masyarakat akan timbul, apabila alam memberikan manfaat baik langsung maupun tidak langsung. Agar dapat memberikan manfaat, maka alam harus dikelola dan dijaga sehingga partisipasi masyarakat penting bagi suksesnya ekowisata di suatu daerah tujuan wisata. Peran aktif masyarakat sangat dibutuhkan dalam pengembangan ekowisata berbasis masyarakat. Hal tersebut didasarkan kepada kenyataan bahwa masyarakat memiliki pengetahuan tentang alam sehingga pelibatan masyarakat sangat diperlukan. Pola ekowisata berbasis masyarakat bukan berarti masyarakat akan menjalankan usaha ekowisata sendiri tetapi bekerjasama dengan pihak lain seperti desa dan Perum Perhutani (Hijriati 2014). Pengelolaan wisata berbasis masyarakat tidaklah akan berhasil apabila legalitas kawasan wisata tersebut masih illegal.

Dalam hal perizinan, pengelolaan Ekowisata Karst Cibadak masih memiliki kendala berupa legalitas pengelolaan kegiatan ekowisata. Saat ini pengelola baru akan membentuk Lembaga Masyarakat Desa Hutan (LMDH) Desa Cibadak. Pengelola sudah mengajukan legalitas pengelolaan melalui mekanisme kerjasama pengelolaan dengan pihak pengelola kawasan hutan, dalam hal ini Perum Perhutani, Kesatuan Pengelolaan Hutan (KPH) Bogor, Divisi Regional Jawa Barat dan Banten. Kerjasama belum terealisasi karena aksesibilitas menuju lokasi harus melewati kawasan yang dikuasai oleh TNI AD atau Kopassus. Permalasahan ini telah coba diselesaikan dengan diadakannya Focus Group Discussion (FGD) pada tanggal 13 Juli 2019 antara pihak Kopassus, Perum Perhutani, pengelola kawasan wisata, warga, perangkat desa (Lurah), Ketua RT dan dari pihak Universitas Nusa Bangsa (Gambar 10,11 dan 12). Hasil FGD adalah pengelola akan membuat sket atau foto-foto penggunaan lahan kopasus yang akan dipergunakan untuk pembangunan fasilitas wisata seperti tempat parkir, camping ground, tempat untuk berjualan, dan sarana prasarana lain yang dianggap perlu. Sket atau foto tersebut akan dibuat laporan oleh pihak Kelurahan dan akan dilaporkan ke pihak Kopasssus. Setelah mendapatkan persetujuan dari Kopassus maka akan dibentuk LMDH yang bekerjasama dengan Perum Perhutani. 


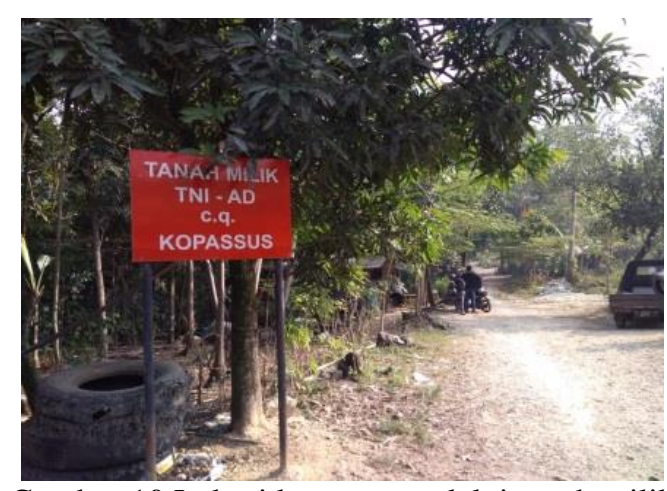

Gambar 10 Lokasi kawasan melalui tanah milik

Kopassus

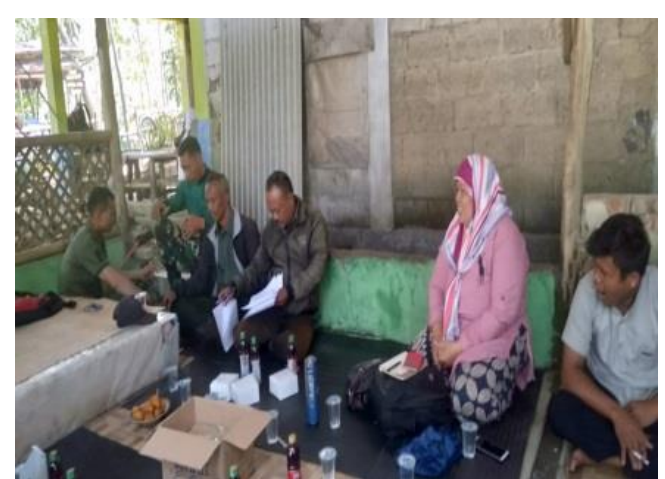

Gambar 11 Suasana saat diadakan FGD

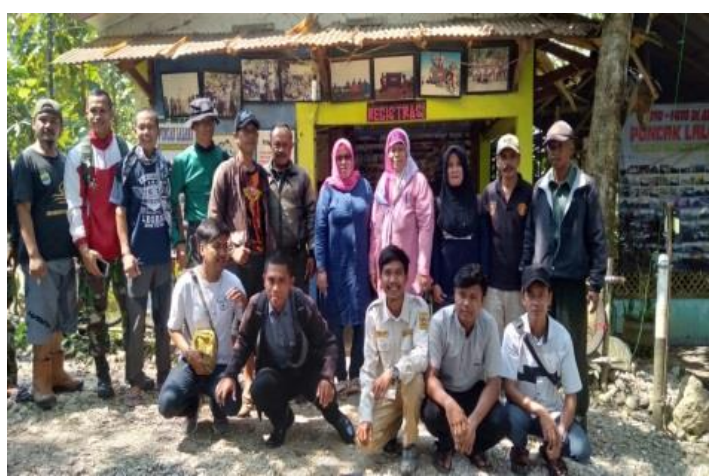

Gambar 12 Suasana setelah diadakannya FGD dengan foto bersama

\section{SIMPULAN}

Kawasan Ekowisata Karst Cibadak dinyatakan layak dikembangkan sebagai daerah tujuan wisata dengan nilai $77,87 \%$. Daya tarik wisata kawasan ini adalah wisata tracking, wisata edukasi dan camping ground, serta daya tarik budaya berupa peninggalan kerajaan Pajajaran. Pengelola kawasan Ekowisata Karst Cibadak beserta perangkat Desa Cibadak akan segera membentuk LMDH setelah disetujuinya permintaan pemakaian lahan oleh pihak Kopassus.

Pengelola dapat menambah fasilitas sarana, prasarana dan memperbaiki jalur pendakian mengingat terjal dan curamnya jalur untuk mencapai Puncak Lalana karena keselamatan dan kenyamanan pengunjung merupakan komponen utama yang harus terpenuhi. Pengelola agar membuat papan-papan interpretasi di sepanjang jalur pendakian. Pengunjung membutuhkan atraksi wisata yang lebih bervariasi sehingga pengunjung tidak merasa jenuh seperti pengamatan flora dan fauna karst, outbond, penelusuran gua dan pengamatan fauna gua

\section{DAFTAR PUSTAKA}

Abdulhaji. 2016. Pengaruh atraksi, aksesibilitas, dan fasilitas terhadap citra objek wisata Danau Tolire Besar di Kota Ternate. Jurnal Penelitian Humano. 7(2):34-148.

Bismark M. 2011. Prosedur Operasi Standar (SOP) untuk Survei pada Kawasan Konservasi. Bogor:
Pusat Penelitian dan Pengembangan Perubahan Iklim dan Kebijakan Badan Penelitian dan Pengembangan Kehutanan, Kementerian Kehutanan, Indonesia Kerjasama dengan International Tropical Timber Organization (ITTO).

Bogordaily. 2017. Dikelilingi 20 Gua, Ini Asal Usul Gunung Kapur Ciampea. [internet] [diunduh 2 mei 2020] Tersedia pada : https://bogordaily.net/2017/11/dikelilingi-20-gua-iniasal-usul-gunung-kapur-ciampea/

Dirjen PHKA. (2003). Pedoman ODTWA. Jakarta: Kementerian Kehutanan.

Endarto R, Gunawan T, Haryono E. (2016). Kajian kerusakan lingkungan karst sebagai dasar pelestarian sumberdaya air (Kasus di DAS Bribin Hulu Kabupaten Gunungkidul Daerah Istimewa Yogyakarta). Majalah Geografi Indonesia. 29(1):5159. https://doi.org/10.22146/mgi.13099.

Hijriati E. 2014. Pengaruh ekowisata berbasis masyarakat terhadap perubahan kondisi ekologi, sosial dan ekonomi di Kampung Batusuhunan, Sukabumi. Jurnal Sosiologi Pedesaan. 2(3):146-159.

Karsudi. 2010. Strategi pengembangan ekowisata di Kabupaten Kepulauan Yapen Provinsi Papua. JMHT. 16(3):148-154.

Kementrian Kehutanan. 2013. Peraturan Direktur Jenderal Bina Pengelolaan Daerah Aliran Sungai Dan Perhutanan Sosial Nomor : P. 4/V-Set/2013 Tentang Petunjuk Teknis Penyusunan Data Spasial Lahan Kritis. 
Khairani F. 2017. Dampak perubahan pemanfaatan Kawasan Karst Gunung Sewu terhadap resiliensi ekonomi rumah tangga di Kabupaten Gunung Kidul [tesis]. Bogor: Institut Pertanian Bogor.

Nawangsari D, Muryani C, Utomowati R. 2018. Pengembangan wisata Pantai Desa Watu Karung dan Desa Sendang Kabupaten Pacitan tahun 2017. Jurnal GeoEco. 4(1):31-40.

Novian. 2010. Perencanaan Lansekap Gunung Kapur Cibadak Ciampea Bogor sebagai kawasan wisata terpadu [skripsi]. Bogor: Institut Pertanian Bogor.

Nuraini. 2013. Kajian karakteristik dan potensi kawasan karst untuk pengembangan ekowisata di Kecamatan Ponjong Kabupaten Gunung Kidul. Jurnal Geomedia. 11(1):109-127.

Peraturan Menteri Energi dan Sumber Daya Mineral Nomor 17 Tahun 2012 Tentang Penetapan Kawasan Bentang Alam Karst.

Prawerti IAD, Mananda IGS, Dewi LGLK. 2015. Faktorfaktor yang mempengaruhi penurunan intensitas kunjungan wisatawan di Daya Tarik Wisata Candidasa, Kabupaten Karangasem, Bali. Jurnal IPTA. 3(1):13-18.
Rusyani. 2014. Pemanfaatan kawasan karst untuk peningkatan kesejahteraan masyarakat [skripsi]. Surakarta: Universitas Muhammadiyah Surakarta.

Sakdiah. 2017. Daya tarik objek wisata alam Pulau Senoa Provinsi Kepulaun Riau. Jurnal Hutan Lestari. 5(1):52-61.

Suharto. 2016. Studi tentang keamanan dan keselamatan pengunjung hubungan dengan citra destinasi. Jurnal Media Wisata. 14(1):287-304.

Walimbo R. 2016. Studi potensi objek dan daya tarik wisata alam Air Terjun Wiyono di Taman Hutan Raya Wan Abdul Rahman, Provinsi Lampung. Jurnal Info Teknik. 17(2):165-186.

Widodo E. 2017. Pengembangan atraksi wisata Pantai Tanjung Karang sebagai kawasan wisata bahari di Kabupaten Donggala. Katalogis. 5(4):206-215.

Zen AR, Sadjati E, Ikhwan M. 2018. Pemetaan potensi ekowisata di Desa Tanjung Belit dan Desa Lubuk Bigau Kecamatan Kampar Kiri Hulu Kabupaten Kampar Provinsi Riau. Wahana Forestra:Journal Kahutanan. 13(1):77-89. 